\title{
Develop a List to Detect the Professional Tendencies of Hearing Impaired Enrolled in Vocational Rehabilitation Programs and Deaf Schools in Jordan
}

\author{
Feryal Abdel- hadi Shanikat ${ }^{1}$ \\ ${ }^{1}$ Special Education, The World Islamic Sciences \& Education University, Amman, Jordan \\ Correspondence: Feryal Abdel- hadi Shanikat, Special Education, The World Islamic Sciences \& Education \\ University, Amman, Jordan.
}

Received: February 20, 2020

Accepted: June 2, 2020

Online Published: December 21, 2020

doi:10.5539/mas.v15n1p12

URL: https://doi.org/10.5539/mas.v15n1p12

\begin{abstract}
The current study aimed to develop a list of professional tendencies and verify the implications of its validity and reliability and know the professional tendencies and impact of gender variables and the degree of disability on hearing-impaired people's professional tendencies. To achieve the objectives of the study, the researcher developed the list of Arabized professional tendencies of John Holland in a way that suits the characteristics of the hearing-impaired and using the previous literature and previous studies, where the indications of validity and reliability were extracted from the pilot study, then the study tool was applied to the final sample, which consisted of (118) hearing-impaired individuals from deaf schools and vocational rehabilitation centers in Jordan who are in the stage of professional selection in cooperation with my translators of sign language of schools and rehabilitation centers, where the study reached the indications of validity and reliability of the study tool, the study also found that there was no effect of gender and degree of disability variable on the professional tendencies of hearing-impaired people, as it came out with a set of research and educational recommendations.
\end{abstract}

Keywords: professional tendencies, hearing-impaired people, revealing vocational tendencies, rehabilitation centers, deaf schools

\section{Introduction}

Attention to the issue of vocational rehabilitation for people with disabilities began through developing programs and improving the quality of services related to vocational rehabilitation and training. It is subject to a set of professional standards that control the conduct of these programs, which aim to develop and improve the capabilities of persons with disabilities, which leads to them entering the practical and professional life as productive human capacities that contribute to the progress of societies according to their capabilities (Dababneh, 2006) as disability is not the responsibility of the state alone. Instead, it is a shared responsibility between the state and society, including its specialized social institutions.

All bodies, institutions, and societies working in the field of care and rehabilitation of the disabled must join hands to solve this category's problems and work to solve these problems. And asking each authority to work to integrate these groups and work to care for them medically, socially, and professionally so that they are beneficial to them and their country, and work to study everything related to them and encourage researchers to study the conditions of these groups. The vocational rehabilitation of persons with disabilities contributes to advancing national development; this is due to the economic return to qualification, which is not limited to exploiting the individual's energies and self-sufficiency in economic terms. Instead, it goes beyond them to provide workforce on the one hand, and direct their idle energies to production, and increase income on the other hand, as a result of the success of the rehabilitation process and the right of persons with disabilities to obtain the appropriate work, there will be a change in people's attitudes and outlook towards them so that they develop from negative to positive.

We do not forget that the rehabilitation process's success, in general, can only be achieved if we consider the conditions of the disabled person, his characteristics, inclinations, abilities, personality traits, level of adaptation, educational level, and degree of disability, the extent of the group's support for him and the community's willingness to provide appropriate opportunities for success for the rehabilitation process, including change 
attitudes and enhance legislation that gives the disabled his human rights, both in the educational and social aspects and in employment opportunities like other citizens and planning for vocational training programs to suit this with the capabilities of the disabled person, his inclinations and the requirements of the local labor market, taking into account economic change and the economic conditions of the environment in which the disabled will live and to take into account the development and change are taking place in some professions and industries. (Al-Sartawi, Abdulaziz, Abu Hilal, Maher, and Al-Qaryouti, Ibrahim, 1996).

Likewise, the correct professional choice must be on scientific grounds consistent with the professional and personal inclinations, psychological, social, and personal preparation for this profession, and the individual patterns available to the individual (Hirschi \& Lage, 2014). In the labor market, consideration must be given to the available employment opportunities and their suitability for persons with disabilities. It is also necessary to focus on individuals with disabilities' characteristics rather than on the work environment. Therefore the professional qualification specialist and the vocational counselor should use multiple strategies to help people with disabilities obtain jobs appropriate to the nature of their disability, whether physical, visual, or mental (Gilbrige \& Stensrud, 2012). Individuals with hearing disabilities have capabilities that enable them to join the labor market and in different fields of work; if their capabilities and inclinations to work correctly are evaluated so that persons with hearing disabilities enter occupations that are commensurate with the degree of their disability, their inclinations, and their personality patterns. And in the field of vocational evaluation, there is an apparent deficiency related to assessing the preferences and capabilities of people with hearing disabilities, which leads to their joining jobs that may not match their tendencies and preparations, and therefore their failure in the labor market.

\section{The Study Problem and Its Importance}

The hearing impaired's rehabilitation stage goes through several steps to reach the final goal, which is employment and obtaining an appropriate profession so that people with hearing disabilities can be independent and depend on themselves and thus integrate with the local community, which is what special education programs aim at. Suppose the inclinations and capabilities of people with hearing disabilities are not evaluated and trained in accordance with their measured capabilities. In that case, this will lead to the failure of the training process, which negatively affects the following steps: employment and obtaining a suitable profession, especially since the profession in the lives of individuals is important as it reflects the individual's lifestyle. It also affects work situations and the personality of the individual, as the profession achieves economic, psychological, and social purposes, where if the individual is placed in an appropriate job, this leads to increased productivity from a psychological point of view, the individual's failure in a profession leads to a feeling of deficiency and frustration. Likewise, unemployment leads to the individual being subjected to psychological and social incompatibility (COOK, 2013). Hence, the researcher's interest in the process of developing a scale that identifies the professional inclinations of people with hearing disabilities, as the field lacks appropriate professional standards to assess the capabilities and inclinations of persons with disabilities in general and those with hearing disabilities in particular - within the limits of the researcher's science - And determine their ability to ensure their success in the professions they are enrolled in. Therefore, the current study came to answer the following questions.

The study problem is represented in the following central question: -

What is the effectiveness of the developed scale in detecting the professional tendencies of persons with hearing disabilities enrolled in vocational rehabilitation centers and deaf schools in Jordan?

The following sub-questions are derived from it:

The first question: What are the implications of the validity of the developed scale in revealing the professional inclinations of people with hearing disabilities, expressed in terms of the contents of validity, global validity, and construction validity?

The second question: What are the indications of the developed scale's stability in the detection of the professional inclinations of people with hearing disabilities, expressed in the half-split and Alpha Cronbach method?

The third question: What are the occupational preferences of students with a hearing disability enrolled in vocational rehabilitation programs and deaf schools on the John V Holland Occupational Preference List?

The fourth question: Are there statistically significant differences at $(\alpha=0.05)$ in performance on the scale of professional tendencies developed attributable to the gender variable (male, female)? 


\subsection{Study Objectives} disabilities.

Develop a scale to determine the range of occupational preferences for people with hearing

- $\quad$ Know the effect of gender on the type of occupational preferences for the hearing disability.

- Know the effect of the type of disability in the kind of occupational tendencies of the hearing disability.

\subsection{The Importance of the Study in Theory}

- $\quad$ Enrich the Arab library in the field of career preferences for people with hearing disabilities. Enrich the Arab library in the field of career preferences for people with hearing disabilities.

- $\quad$ This study helps identify the professional tendencies of people with hearing disabilities.

- Improve the work of trainers in vocational rehabilitation centers through the use of reliable measuring tools.

- $\quad$ Enrich the field of measurement and diagnosis with a professional measuring tool for people with hearing disabilities.

- Work to draw researchers' attention to the issue of professional measures for people with disabilities.

\subsection{The Importance of the Study from a Practical Point of View}

- $\quad$ Provide a tool to measure the professional inclinations of people with hearing disabilities, which contributes to the rehabilitation process's success and the integration process's success.

- $\quad$ Expose realistic professional tendencies for people with hearing disabilities.

- $\quad$ Provide appropriate professional training for each hearing disabled person.

- Build a vocational rehabilitation plan based on a realistic evaluation process for people with hearing disabilities.

- Develop and diversify vocational training programs for people with hearing disabilities, which requires students' capabilities and current scientific progress.

\section{Conventional and Procedural Definitions}

Development: making changes to the Holland professionalism scale. In proportion to the characteristics of the category of persons with hearing disabilities.

Occupational Inclinometer: The researcher's scale was developed based on John Holland's professional preferences list.

People with hearing disabilities: A person with a hearing loss of $70 \mathrm{~dB}$ or more and impedes speech comprehension. With the ear alone, with or without the use of a stethoscope (Moores, 2008).

Procedurally: They have hearing disabilities enrolled in vocational rehabilitation centers in Jordan and deaf schools and are in secondary education who have hearing disabilities or have a hearing impairment.

Disclosure: It is a quick procedure for identifying cases of disability (Rusan, 2018).

They are procedurally defined: Determining the field of professional tendencies for the hearing impaired who are enrolled in vocational rehabilitation centers and deaf schools in Jordan based on their grades on the scale prepared by the researcher for the study.

Hearing disability schools: procedurally defined: The government schools affiliated with the Ministry of Education provide services for people with hearing disabilities in all governorates of the Hashemite Kingdom of Jordan.

Vocational rehabilitation centers: They are procedurally defined: The centers provide vocational rehabilitation services for individuals with hearing disabilities in Jordan.

\section{The Limits of the Study}

Spatial limits: The study is limited to centers and schools for people with hearing disabilities that provide vocational training services for people with hearing disabilities in Jordan.

Time limits: The first semester of the academic year 2017/2018. 
Human limits: The study is limited to those with hearing disabilities enrolled in vocational training centers in the stage of vocational evaluation and those with hearing disabilities in the tenth grade in schools with hearing disabilities in Jordan.

Objectivity limits: The study is limited to studying the effectiveness of the scale developed by the researcher (a measure of the professional inclinations of people with hearing disabilities), knowing the patterns of occupational inclinations for people with hearing disabilities, and studying the effect of gender on performance on the developed scale.

\subsection{Study limitations}

- The study tool used (A measure of the professional inclinations of people with hearing disabilities) in terms of validity and reliability.

- The extent of cooperation of the sample members.

\section{Theoretical Framework}

\subsection{Rehabilitation}

Rehabilitation is that organized and stable process that aims to reach the disabled individual to the maximum degree possible from the medical, social, psychological, educational, and economic aspects. One of the most common definitions is the definition established by the National Rehabilitation Council in America in 1942 and still found by workers in this field; this definition indicates that rehabilitation means the ability of a person with a disability to recover to his full ability to benefit from his physical, social, mental, professional and economic capabilities.

The international organization-defined qualification as taking advantage of a group of organized services in the medical, social, educational, and professional evaluation fields to train and retrain an individual and to reach him to the highest level of job ability, as for the rehabilitation process, it is the organized process that aims to benefit the disabled person and grow physically, mentally, and sensually. And He can work and spend a useful life in the social, personal, and economic aspects.

The International Labor Organization has also defined vocational training as providing vocational guidance and training services for persons with disabilities to obtain appropriate employment opportunities, achieve autonomy, empower and integrate them into the societies to which they belong (Al-Zumot, 2005). (Al-Zari, 2006) defined it as the process by which persons with disabilities are assisted to reach critical and crucial decisions related to their career prospects and helping them to reveal their professional abilities, which can be used as much as possible in the process of learning and training in a profession for the benefit of them and society. According to their capabilities to join a profession, most of the definitions previously mentioned focused on providing appropriate services for people with disabilities to reach independence and self-reliance, which is what special education services generally seek.

\subsubsection{Justification for Qualification}

- $\quad$ Regardless of their disability, a person is considered a maker of civilization, and thus should be a direct goal of the areas of comprehensive development.

- $\quad$ A disabled person is considered an individual who can participate in development efforts.

- The comprehensive development of rehabilitation is part of it, and the development required in the economic and social structures is considered an essential pillar in eliminating the causes of disability in its various forms.

- Disabled people, regardless of their disability and their categories, differ; they have the ability, capabilities, and motivation to learn, grow, and integrate into society's ordinary life. Therefore, it is necessary to focus on developing their potentials and abilities in learning and participation.

- $\quad$ All persons with disabilities have the right to care, education, rehabilitation, and employment.

- The rehabilitation process is a right for the disabled in the field of equality with other citizens. (Hein, 2005). 


\subsection{Types of Rehabilitation}

\section{Medical Rehabilitation}

It is the process of returning a disabled person to the highest possible level of employment physically or mentally by using medical skills to reduce and eliminate disability if possible. Medical rehabilitation services include surgery, drug treatment, and the use of assistive devices.

\section{Social and Psychological Rehabilitation}

It is the process of returning a disabled person to the highest possible level socially and psychologically through psychotherapy and family counseling.

\section{Academic Rehabilitation}

It teaches people with academic disabilities according to their abilities and the degree of their physical and mental disabilities and provides them with the necessary academic skills that benefit them in their working life, such as proficiency in reading and writing, numeracy or daily life activities.

\section{Vocational Rehabilitation}

The vocational rehabilitation process is a sequential series of services designed to move the disabled person toward employment in a profession commensurate with his inclinations and abilities. Vocational rehabilitation is an essential and important part of the vocational rehabilitation process for the disabled and includes any training that may be necessary for rehabilitation and preparing the disabled for appropriate and successful employment (Zureikat, 2015).

\subsubsection{Stages of Vocational Rehabilitation}

Vocational rehabilitation services for the disabled include the following steps:

\section{Referral:}

After identifying the cases, they are referred to the vocational rehabilitation services to take the tests and apply the measures to start the appropriate vocational training programs.

\section{Registrations:}

Upon transferring the disabled person to vocational rehabilitation centers, the specialists receive and register the disabled person initially, after which he is interviewed by the social worker, the medical committee, the professional specialist, the psychologist. Where specialists evaluate various aspects of the situation to determine the possibility of rehabilitation and determine the appropriate profession for the condition of the individual where the knowledge aspects are considered through (IQ tests such as Stanford interstitial) and also assess the social aspect of the social worker through the use of measures (adaptive behavior).

Professional guidance is concerned with helping the disabled person choose a suitable profession for him to prepare himself for, join, and progress in; vocational rehabilitation begins from the first interview and ends with the end of the vocational rehabilitation process, and the forms of vocational guidance and counseling differ in different stages or steps of vocational rehabilitation. Vocational rehabilitation services seek to help the disabled person to make a proper choice of a profession or a suitable craft for him that is appropriate to his capabilities and energies. The characteristics of his personality, the nature of his disability, and the conditions imposed by him, and provide him with the necessary professional information to help him make a professional choice, provide him with various professional experiences and observe his behavior towards each of them to determine his desires and inclinations, and this process can be summarized with what we call Matching. Between specific professional requirements or a job, and the characteristics, capabilities, and inclinations of a disabled person to suit specific job requirements or a craft of what a disabled person wants to train in, we must help him adapt and comply with the demands of vocational training for work. (Morsi, 1983).

With the recent progress in providing transitional programs for people with hearing disabilities, people with hearing disabilities have become enrolled in different jobs and professions that require those in charge to develop assessment methods commensurate with the progress witnessed in the transitional and educational programs so that it can reveal the latent abilities of deaf individuals, which helps to present a brighter image to them (Jarwan, Fathi, Musa, Amayreh, Ghaleb, Al-Hayari, Hatem A Al-Khumara, Qais, Miqdad, Shaden, Alywat, Suha, Al-Tabbal, Safaa, Al-Ali, 2013). 


\subsubsection{Vocational Training}

Vocational training is considered one of the most important rehabilitation services, whose programs seek to give the disabled person the ability to pursue work and work in it. There is no doubt that vocational training works to prepare disabled workers like other society members who can produce and bear the working conditions and consider them one of society's human energies. Vocational training is considered the backbone of the vocational rehabilitation process, and if the vocational training process is successful and effective, it will lead to successful employment.

\section{Steps in the vocational rehabilitation process:}

Professional evaluation: It is a process that aims to identify the capabilities, inclinations, and preparations of the disabled individual to help him to make a professional choice within the limits of their programs in vocational rehabilitation centers. In this step, a number of professional measures and tests are used to predict the professional fields that suit the preparations and capabilities of the disabled person (Rihani, 2010).

Occupational Guidance: Based on the results of the professional evaluation, the appropriate professional direction is provided for the inclinations and preparations of the hearing disabled person.

Vocational training: Vocational training is conducted based on the results of a professional evaluation.

Professional employment: It is the admission to a job or profession appropriate to the inclinations and abilities of the hearing disabled person.

The vocational rehabilitation process goes through several steps, and as we note, the vocational evaluation is the first step in the qualification process, and the success of this step leads to the success of the next steps; by referring to theoretical literature and the field, the researcher found a significant deficiency in the field of assessing tendencies and preparations for people with disabilities, especially hearing disabilities.

\section{Professional evaluation for the hearing disabled}

The evaluation is defined as determining an individual's eligibility for a disability and the appropriateness of vocational rehabilitation plans for the individual candidate for vocational education. As the professional evaluation for people with disabilities includes psychometric tests, work samples, self-reports, and work environment analysis and most evaluation methods focus on giving an image of a person's physical abilities to obtain a job or maintain a job (Langman, 2012).

\section{Professional inclination}

Professional inclination: It is the individual's preference for a certain profession or job based on preconceived notions, certain perceptions, or personal (psychological) characteristics. Professional inclination, according to the classification of John Holland, means one of the aspects of personality. The description of an individual's professional inclination is only a description of his personality, and the personality traits of an individual can indicate the appropriate profession for him (Holland, 1973).

\section{Holland's theory of professional inclination}

According to the individual's activities, Holland divided personality patterns into six sections and work environments into the same sections. He believes that individuals in a specific work environment tend to perform similar activities, and their characteristics will also be similar. Holland believes that each individual belongs to one particular model and that his actions are similar to some aspects related to one or two other models in dealing with the environment in which he lives. And if the individual tends to perform certain activities, he hates carrying out other activities, and the six patterns that Hollande proposed are the realistic style, the analytical pattern, the artist style, the social style, the clear pattern, and the traditional style. Besides these patterns, there are six environments: the real environment, the analytical environment, the technical environment, the social environment, the persuasive environment, and the traditional environment. It is itself the six personality styles. (Spokane \& Cruza-Guet, 2005).

\section{Professional personality styles and their corresponding professional environments:}

Personality and professional mental environment: This personality tends to think more than work, and to understand more than control to deal with ideas, symbols, and words, it avoids social situations, and working with the professional mental environment requires creative scientific, mental, analytical and mathematical ability, such as computer and mathematical and statistical professions. And prefer to deal with tangible things more than abstract things, personal and realistic professional environment: The realistic personality tends to work that needs physical strength more than mental focus, and prefer to deal with tangible things more than abstract things, 
it lacks the skill of social communication, and the preferred professional environment for people with a realistic style is the environment that needs manual, technical and mechanical skills such as industrial and agricultural occupations.

Personality and social environment: this character tends to activities of a social nature and attitudes that need social communication skills such as verbal and emotional skills and take responsibility. Working in the social environment requires high skills to communicate with others and build social relationships in the education environment.

Personality and traditional professional environment: This personality tends with a high ability to exercise self-control and extreme attention to regulations and avoid activities that require high social skills, and work in the traditional professional environment requires systematically developing data in the performance and following instructions such as accounting, business, and banking professions.

Personality and adventurous professional environment: This character tends to be able to use verbal and social skills to control, lead and search for status and social leadership; working with them requires the skills of persuading and leading others, including political works, formal and informal departments, and real estate offices.

Personality and professional technical environment: Tends to use feelings, avoiding situations that need organizational skills, physical strength, high verbal skills, and a low ability to exercise self-control, working in the technical environment requires the use of creative skills based on feelings and imagination; For self-expression, among these professions are literary and musical works, art and poetry (Al-Shehri, 2010).

\section{Persons with hearing disabilities}

Several definitions of hearing disability appeared due to the multiplicity of views that addressed hearing disability. The most prominent of these definitions are medical definitions. Where the hearing disabled person was known as that individual whose organ hearing system was damaged, and organic defect prevented him from using it in public life as normal as other ordinary individuals, and this means that the defect or damage has affected the outer, middle or inner ear, this, of course, may not include all parts of the ear, but part or parts of it.

As for the educational point of view, the hearing impaired was defined as that person who cannot rely on the sense of hearing to learn the language or benefit from the various educational programs offered to the listeners. And he needs educational methods to compensate him for the sense of hearing. As for the hearing impaired, it is that a person who suffers from a loss of auditory ability may be able to replace it with hearing aids, and the high volume of sound and he can learn in the same way that hearing individuals learn after using the hearing aid (Zureikat, 2015).

\subsubsection{Rehabilitation of Persons with Hearing Disabilities}

Among the general principles underlying the vocational rehabilitation program for people with hearing disabilities:

Hearing-impaired individuals enjoy all the rights and duties of the ordinary citizen, including rights of respect and dignity, humane treatment, and the provision of appropriate education, training, and rehabilitation opportunities.

A hearing-impaired person has his own distinct needs and desires, like all people.

A successful vocational Rehabilitation process is the process that ensures the active participation of a person with hearing impairment in its design, implementation, and evaluation (Al-Khatib, 2002).

\section{Types of professional evaluation for the hearing impaired}

- Interview

- Skills Analysis

- Use medical records and appropriate standards

- Job evaluation

- Job evaluation during work (Zureikat, 2015).

Among the measures used to assess hearing impaired people are:

- Webman scale for auditory discrimination

- Lindamood and Dock scale for audio discrimination 
- Goldman Firststo Auditory Discrimination Scale (Rusan, 2018).

Some measures that measure the ability of persons with disabilities in general to enter a profession include:

Motor coordination readiness: It is a test that measures the consistency of the movement of eyes, hands, and fingers quickly and accurately when making specific movements and also measures the accuracy of the response.

Use dexterity and accuracy: It is a test that measures the ability required to perform the work accurately, as it measures the number of movements and the necessary degree of mastery, and these movements have a specific probability of error (Al-Ali, 2010).

Numerical power readiness: It measures the ability to perform calculations quickly and accurately

Performance test: It is a test that requires a kinetic or manual response, which includes the use of equipment and materials related to a specific profession, and the ability of people with disabilities to use this equipment is measured.

The previously mentioned scales are scales used to assess auditory discrimination and are mostly suitable for lower age groups. Also, intelligence measures known as Wexler and Stanford's scale are not valid for determining the hearing impaired, as they include two dimensions, the verbal dimension and the performance dimension. Where the hearing impaired does not possess the language, these measures are not suitable for assessing their cognitive abilities, and within the limits of the researcher's knowledge, there is a dearth of professional standards codified for people with hearing disabilities. Previous Arab and foreign studies that the researcher could obtain through research evidence bases and university theses will be presented.

Some of them relate to vocational rehabilitation, precisely the aspect of professional evaluation, and some relate to the list of occupational preferences. Previous studies will be presented from the oldest to the most recent according to two groups, namely:

The first group consisted of studies on the vocational rehabilitation and evaluation of persons with hearing disabilities.

The second group: consisted of the studies that dealt with Holland's professional tendency scale's psychometric properties.

First: The first group: studies that dealt with the professional rehabilitation of persons with hearing disabilities.

Abdul Qadir study (2003) aimed to identify the criteria for vocational rehabilitation for the hearing impaired, the extent of their application in vocational rehabilitation centers in Jordan, and the obstacles to their application. The study sample consisted of hearing-impaired male and female graduates (1998-2001) in Jordan's vocational rehabilitation centers, and they numbered 57. To achieve this, four questionnaires were developed. The results showed that there are not available criteria in the centers, such as measuring tools and appropriate tests for each category of disability.

The Homa study, 2004, aimed to identify the characteristics of persons with disabilities who are most likely to receive professional evaluation services and learn about the role of vocational evaluation services in the vocational rehabilitation centers' career and professional outcomes in Chicago. The researcher conducted a longitudinal study on the vocational rehabilitation services and programs for people with disabilities, where the study indicated a set of results, the most prominent of which is the opportunities for individuals with disabilities who have accessed vocational evaluation services which are more likely to obtain employment opportunities than those who did not receive vocational evaluation services.

Walter and Bochner's study (2005) aimed to uncover alternative methods for assessing students' readiness with hearing impairment to keep up with post-secondary English learning. The study sample consisted of (905) students with auditory disabilities who responded to the reading test (ACT) and the NTTD integration test, where the results showed a deficiency in the evaluation measures used, as they do not take into account the characteristics of students with hearing disabilities.

(Kavin \& Kurz, 2008) the study aimed to uncover the experiences and expertise of deaf supervisors and professionals in supervisory and educational sites and the disclosure of the most important ways and methods to qualify them. The study sample consisted of (11) supervisors in New York City, where the sample consisted of (3 supervisors) and (8 female supervisors), whose ages ranged between (30-50) years and in order to achieve the objectives of the study, video interviews were conducted with the sample members. The study results showed that the hearing disability among the sample members constitutes a major obstacle in their professional progress. 
They showed their satisfaction with some of the institutions that use modern communication means and technology, which leads to their professional advancement.

Obaid study (2009) aimed to know the efficiency of vocational rehabilitation centers' services for people with visual impairments and those with disabilities, physical disability in the West Bank, and building a strategy to develop it. The study sample included (153) responsible supervisors. The beneficiaries of visual impairment (70) and the beneficiaries of physical disabilities, who reached (111) and persons with visual impairments who graduated from the centers and workers (23) and persons with physical disabilities who graduated from the centers and workers, numbering (23), and accordingly the sample of the final study reached (380) the study reached the following results: The obstacles that limit the efficiency of the services of vocational rehabilitation centers for people with visual impairments and those with physical disabilities in the West Bank are focused on a lack of financial support budgets, and the lack of annual development plans in society that are concerned with the rehabilitation of persons with disabilities professionally, and the scarcity of appropriately qualified cadres in the field of vocational rehabilitation for persons with disabilities, the presence of architectural obstacles in the buildings, the scarcity of tools and standardized tests on the Palestinian environment that are used for the purposes of diagnosing and assessing the inclinations and capabilities of persons with disabilities, and the lack of national programs and institutions aimed at the rehabilitation of persons with disabilities professionally, and the lack of awareness of families of persons with disabilities about rehabilitation.

A study by (Baranaustiene, Radzeviceene, Valaliekne \& kosseka2012) aimed to reveal the methods used by teachers of students with disabilities in implementing vocational counseling programs in schools with disabilities, And the effect of using these methods and methods to improve student performance behavior to qualify them and join them in the labor market, the study sample consisted of (12) experts who were chosen from different countries. The study was conducted in Sweden, where the results indicated the importance of professional advice in orienting students with disabilities to the job market. The study also showed that the use of methods suitable for people with disabilities is reflected in their capabilities and positive behavior in the labor market.

\section{Second: The second group: studies that dealt with the psychometric properties of Holland's measure of occupational inclinations.}

Abdel-Hamid study (2003), which aimed to reveal differences in professional attitudes according to the variables of specialization and academic achievement, the Holland Professional Preference Scale was applied to a sample of (270) students in the United Arab Emirates. The psychometric properties of the honesty and reliability scale were verified, and the results also showed differences among students in different disciplines in occupational preference, where the results were in favor of the science in the mental style, in favor of literary specialization in the social style, in favor of industrial specialization in the realistic style, and in favor of commercial specialization in the adventurous style.

A study (Sverko \& Toni, 2006) aimed at verifying the validity of Holland's theory and the validity of Holland's list of career preferences in Croatian society, the study was conducted on a sample of Croatian students in middle and high school. Of different ages, they numbered (1866) students using Holland's list of career preferences. The study tool showed high stability on all menu styles, and the validity of the list structure was verified. Hence, the hypothesis of the Holland model related to the professional orientations of the study sample was validated. The results showed that the students' results on the Holland list of professional tendencies could be used in planning future educational programs and supported the sincerity of Holland's theory and its usability in the Croatian society.

Al-Masoudi study (2007), which aimed to verify the psychometric properties of the scale of occupational inclinations on a sample of secondary school students in Saudi Arabia, the study instrument was applied to a sample of (1738) male and female students from the secondary stage in the Tabuk region in Saudi Arabia. The results indicated that the vocational inclinometer has high sincerity and consistency, the results showed that coefficients of internal consistency between them confirmed the hexagonal form of the various professional environments of Holland.

A study of (Ohashi, 2009) aimed to research the effectiveness of Holland's list of occupational preferences, and Holland's hexagonal model (RIASEC) as a useful identification tool for Japanese high school students in American schools, to restrict career options and develop their own professional identity. And on how students react to the tool depending on the differences by gender, the attitudes towards searching for work. The study sample consisted of (58) male and female Japanese students residing in America. The results showed a statistically significant relationship between obtaining high degrees in professional identification and using appropriate tools to explore occupational tendencies. It also showed that there were no statistically significant 
differences for sex, and the results of the study supported the effectiveness of using the Holland model (RIASEC) in the indicative intervention.

Al-Shehri's study (2010), which aimed to Arabize, legalize and define psychometric properties and derive performance criteria for the VPI of John Holland in the Saudi environment, the list was applied to a sample of (765) male and female students in the secondary stage, who were randomly chosen from the Qurayyat region, the results indicated that the males showed a tendency towards patterns: realism, masculinity, and scarcity, while females showed a tendency towards patterns: research, artistic, social, femininity, prestige and submission. The study concluded that the list's psychometric properties are acceptable to the types of occupations in the Saudi environment.

Al-Masoudi and Tannous's study (2015) aimed to codify the Vocational Preference Inventory-VPI for John Holland of the Jordanian environment by verifying its validity, reliability, and deriving performance criteria against it. The study was applied to a randomly chosen sample, stratified cluster method, as the number of its members reached (2252) male and female students (1133) male and 1119 male and female students. The scales of professional personality patterns indicated the increase of male inclination on the researcher, realist, and enterprising standards. Simultaneously, the female showed a rise in the researcher's inclination, technical and social measures; as for the results of the scales of personality patterns, the results indicated the high inclination of males on measures: submission, scarcity, and self-control. The results showed that the list, in its Jordanian image, has high sincerity, consistency, and applicability, and use in the Jordanian environment.

Through reviewing previous studies, the researcher found that most of the previous studies dealt with the following:

Some of the previous studies were interested in identifying rehabilitation and vocational evaluation services, such as the study (Homa (2004). Baranaustiene, Radzeviceene, Valaliekne \& kosseka2012), where the studies found a lack of professional evaluation for people with hearing impairments.

- Some studies have examined assessing the aptitude of hearing-impaired students in aspects of language, such as the study (Walter, Bochner, 2005).

- Some studies dealt with the issue of verifying the effectiveness of Holland's theory on a sample of ordinary people (such as (Ohashi, 2009) and Sverko \& Toni, 2006)), but there are no studies that deal with people with hearing disabilities.

\section{The present study was distinguished from the previous studies in the following:}

- $\quad$ Find a scale with psychometric characteristics to assess the professional tendencies of the hearing impaired in Jordan.

- $\quad$ Find a scale based on Holland's theory that aims to evaluate hearing-impaired people's professional tendencies, where there is a clear deficiency in the field of assessing the professional tendencies of people with disabilities, especially those with hearing disabilities.

- $\quad$ Learn about the professional tendencies of people with hearing-impairment.

- Identify the impact of gender and the degree of disability in people with hearing impairments' occupational preferences.

\section{Method and Procedures}

\section{Study Approach}

The relational descriptive approach was used to suit the study objectives, knowing people's professional preferences with hearing impairment and its association with some variables.

\section{The population of the study}

The study population consists of hearing-impaired persons enrolled in vocational training centers (in the stage of assessing occupational tendencies) and deaf schools in the Hashemite Kingdom of Jordan, and they are (140), as the number of students in the vocational selection stage in the tenth grade and above reached (70) students from almost all governorates of the Kingdom, according to the statistics of the Ministry of Education for the year 2018. As for the number of students enrolled in vocational rehabilitation centers in the vocational evaluation stage, approximately (70) individuals according to general statistics of 2018. 


\section{The Study Sample}

The study sample consisted of (118) hearing-impaired individuals enrolled in rehabilitation centers and deaf schools in the Hashemite Kingdom of Jordan, and Table (1) clarifies the characteristics of the sample.

Table 1. Characteristics of the study sample

\begin{tabular}{llll}
\hline Variable & & Frequency & Percentage \\
\hline Gender & Females & 58 & 49.2 \\
& Males & 60 & 50.8 \\
Total & & 118 & $\% 100.0$ \\
The degree of impairment & Minor & 28 & 23.7 \\
& Moderate & 40 & 33.9 \\
& Severe & 50 & 42.4 \\
Total & & 118 & $\% 100.0$ \\
\hline
\end{tabular}

\section{Study tool}

The study tool was developed using the Holland Professional Measure Scale. The researcher referred to the following sources to build the scale in proportion to the characteristics of people with hearing disabilities:

- Theoretical literature on the subject of the Professional Tendencies scale, especially the Holland scale.

- The use of Arab and foreign studies in the field of Holland scale of professional Tendencies.

- Some scales were used in the field of the tendencies and professional capabilities of the hearing impaired.

- The use of theoretical literature related to the characteristics of the hearing impaired and their professional rehabilitation.

- Refer to all the scales related to the Holland scale of professional tendencies, including the list of professional preferences for Holland by Dr. Siham Abu Eita, where prior approval was taken to use the scale to develop people with hearing disabilities. The researcher has modified some items and some dimensions to suit the characteristics of people with hearing disabilities because they lack a language; certain occupations suit their abilities and aptitudes. Professions that are not suitable for their capabilities need to be adapted.

- The scale was prepared in its initial form, as the scale consists of (66) items divided into (6) dimensions, namely:

1. Realistic style: includes (10) professions, and includes the following items: $(1,7,16,21,30,38,42$, $48,57,61)$.

2. Mental style: includes 9 professions and includes the following items: - $(2,8,17,26,34,39,43,52$, $62)$.

3. Social style: includes 12 professions, and includes the following items $(3,9,13,18,22,27,31,35$, $44,49,53,63)$.

4. Traditional style: includes 13 professions, and includes the following items: $(4,10,19,23,28,32$, $36,40,45,50,54,58,64)$.

5. Adventurous style: includes 11 professions, and includes the following items: $(5,11,14,20,24,29$, $37,46,55,59,65)$.

6. Technical style: includes 11 professions, and includes the following items: $(6,12,15,25,33,41,47$, $51,56,60,66)$.

7. The scale was presented to a group of specialized arbitrators at universities and centers for vocational training, and an amendment was made to the linguistic wording of some paragraphs.

8. The scale was also applied to a survey sample of (20) male and female students in the professional selection phase from outside the study sample, where the scale was applied to the individuals of the sample with the help of a sign language interpreter to ensure the effectiveness of the paragraphs and take notes on the scale.

In order to ensure clarity of instructions and items, and to determine the time needed to apply the scale, in addition to making sure of the effectiveness of the items before applying to the final sample, Table (2) indicates 
the results of linking the items with their dimensions calculated through the exploratory sample to ensure the effectiveness of the items; where all the items and its dimensions were arranged in a statistically significant way.

Table 2. Measuring the effectiveness of the items

\begin{tabular}{|c|c|c|c|c|c|c|c|}
\hline Item & Correlation & Item & Correlation & Item & Correlation & Item & Correlation \\
\hline 1) & \multicolumn{2}{|c|}{ Realistic style } & \multirow[b]{2}{*}{$.45^{*}$} & \multirow[b]{2}{*}{42} & \multirow[b]{2}{*}{$.87 * *$} & \multirow[b]{2}{*}{61} & \multirow[b]{2}{*}{$.92^{* *}$} \\
\hline 1 & $.94 * *$ & 21 & & & & & \\
\hline 7 & $.85^{* *}$ & 30 & $.40^{*}$ & 48 & $.81^{* *}$ & & \\
\hline 16 & $.35^{*}$ & 38 & $.55^{*}$ & 57 & $.80^{* *}$ & & \\
\hline 2) & \multicolumn{2}{|l|}{ Mental style } & & & & & \\
\hline 2 & $.63^{* *}$ & 26 & $.54^{*}$ & 43 & $87^{* *}$ & & \\
\hline 8 & $.93^{* *}$ & 34 & $.88^{* *}$ & 52 & $.88^{* *}$ & & \\
\hline 17 & $.92^{* *}$ & 39 & $.74^{* *}$ & 62 & $.77^{* *}$ & & \\
\hline 3) & \multicolumn{2}{|l|}{ Social style } & & & & & \\
\hline 3 & $.51 *$ & 18 & $.63^{* *}$ & 31 & $.37^{*}$ & 49 & $.87 * *$ \\
\hline 9 & $.66^{* *}$ & 22 & $.60 * *$ & 35 & $.39 *$ & 53 & $.84 * *$ \\
\hline 13 & $.43 *$ & 27 & $.73^{* *}$ & 44 & $.78^{* *}$ & 63 & $.76^{* *}$ \\
\hline 4) & \multicolumn{2}{|c|}{ Traditional style } & & & & & \\
\hline 4 & $.61^{* *}$ & 28 & $.41 *$ & 40 & $.92 * *$ & 54 & $.87^{* *}$ \\
\hline 10 & $.65^{* *}$ & 32 & $.45^{*}$ & 45 & $.92 * *$ & 58 & $.90^{* *}$ \\
\hline 19 & $.53 *$ & 36 & $.42 *$ & 50 & $.88^{* *}$ & 64 & $.86^{* *}$ \\
\hline 23 & $.39 *$ & & & & & & \\
\hline 5) & \multicolumn{2}{|c|}{ Adventurous style } & & & & & \\
\hline 5 & $.84 * *$ & 20 & $.49^{*}$ & 37 & $.56^{*}$ & 59 & $.91 * *$ \\
\hline 11 & $.57^{*}$ & 24 & $.50^{*}$ & 46 & $.87 * *$ & 65 & $.89 * *$ \\
\hline 14 & $.68 * *$ & 29 & $.38^{*}$ & 55 & $.87 * *$ & & \\
\hline 6) & \multicolumn{2}{|c|}{ Artistic style } & & & & & \\
\hline 6 & $.62 * *$ & 25 & $.35^{*}$ & 47 & $.92 * *$ & 60 & $.90 * *$ \\
\hline 12 & $.66^{* *}$ & 33 & $.40^{*}$ & 51 & $.90 * *$ & 66 & $.94 * *$ \\
\hline 15 & $.40 *$ & 41 & $.90^{* *}$ & 56 & $.91^{* *}$ & & \\
\hline
\end{tabular}

* Significant at .05 level

** Significant at 001 level

The final image consisted of the scale after taking into account the observations of the arbitrators of 6 dimensions: the first dimension, which consists of (10) occupations, the second dimension, which consists of (9) professions, and the third dimension where it is (12) professions. The fourth dimension consists of (13) professions, the fifth dimension (11) professions, and the sixth dimension consists of (11) professions.

\section{Results of the Study}

The first question: What are the implications of the developed scale's validity in revealing the hearing impaired's professional tendencies, expressed in terms of the content validity, factor validity, and construction validity?

\section{First: Arbitrators validity (content)}

the content validity was extracted by displaying the scale to (10) arbitrators from faculty members in Jordanian universities (University of Jordan, Al-Balqa Applied University, The World International Islamic Sciences University) and sign language translators, the trainers in the centers for the hearing impairment were asked to evaluate the suitability of the items to what they were designed to measure, and the clarity of the formulation of the items, after informing them of the goals of the scale, and then proposing the appropriate amendments, and the 
criterion of the agreement of eight arbitrators was adopted to indicate the validity of the paragraph and its suitability to remain within the scale, and the agreement of two arbitrators on its lack of clarity to amend it, and based on the opinions of the competent arbitrators, some of the items were modified in terms of formulation and separating some of their items, which included two items with an item to increase the clarity of the items, as no item was added, but some inappropriate items were deleted to suit the study sample, where an agreement $(80 \%)$ was approved.

\section{Second: construction validity (internal consistency)}

The correlation coefficient of each item was calculated with the dimension to which it belongs to measure the scale's internal consistency as an indicator of the construction's validity, and Table (3) indicates the correlation coefficients.

Table 3. Items correlation coefficients with dimensions as an indication of construction validity

\begin{tabular}{|c|c|c|c|c|c|c|c|}
\hline Item & Correlation & Item & Correlation & Item & Correlation & Item & Correlation \\
\hline 1) & Realistic style & & & & & & \\
\hline 1 & $.682^{* *}$ & 21 & $.647^{* *}$ & 42 & $.564^{* *}$ & 61 & $.735^{* *}$ \\
\hline 7 & $.573^{* *}$ & 30 & $.337^{* *}$ & 48 & $.528^{* *}$ & & \\
\hline 16 & $.620^{* *}$ & 38 & $.730^{* *}$ & 57 & $.748^{* *}$ & & \\
\hline 2) & Mental style & & & & & & \\
\hline 2 & $.514^{* *}$ & 26 & $.646^{* *}$ & 43 & $.628^{* *}$ & & \\
\hline 8 & $.512^{* *}$ & 34 & $.671^{* *}$ & 52 & $.557^{* *}$ & & \\
\hline 17 & $.533^{* *}$ & 39 & $.455^{* *}$ & 62 & $.662^{* *}$ & & \\
\hline 3) & Social style & & & & & & \\
\hline 3 & $.423^{* *}$ & 18 & $.436^{* *}$ & 31 & $.528^{* *}$ & 49 & $.679^{* *}$ \\
\hline 9 & $.330^{* *}$ & 22 & $.560^{* *}$ & 35 & $.342^{* *}$ & 53 & $.474^{* *}$ \\
\hline 13 & $.328^{* *}$ & 27 & $.520^{* *}$ & 44 & $.496^{* *}$ & 63 & $.503^{* *}$ \\
\hline 4) & Traditional sty & & & & & & \\
\hline 4 & $.563^{* *}$ & 28 & $.600^{* *}$ & 40 & $.668^{* *}$ & 54 & $.382^{* *}$ \\
\hline 10 & $.518^{* *}$ & 32 & $.518 * *$ & 45 & $.723^{* *}$ & 58 & $.797^{* *}$ \\
\hline 19 & $.603^{* *}$ & 36 & $.688^{* *}$ & 50 & $.704^{* *}$ & 64 & $.659^{* *}$ \\
\hline 23 & $.713^{* *}$ & & & & & & \\
\hline 5) & Adventurous $\mathrm{s}$ & & & & & & \\
\hline 5 & $.621^{* *}$ & 20 & $.439^{* *}$ & 37 & $.631^{* *}$ & 59 & $.654^{* *}$ \\
\hline 11 & $.655^{* *}$ & 24 & $.591^{* *}$ & 46 & $.679^{* *}$ & 65 & $.615^{* *}$ \\
\hline 14 & $.411^{* *}$ & 29 & $.418^{* *}$ & 55 & $.359^{* *}$ & & \\
\hline 6) & Artistic style & & & & & & \\
\hline 6 & $.619^{* *}$ & 25 & $.581^{* *}$ & 47 & $.676^{* *}$ & 60 & $.682^{* *}$ \\
\hline 12 & $.436^{* *}$ & 33 & $.667^{* *}$ & 51 & $.638^{* *}$ & 66 & $.707^{* *}$ \\
\hline 15 & $.568^{* *}$ & 41 & $.542^{* *}$ & 56 & $.400^{* *}$ & & \\
\hline
\end{tabular}

* Significant at .05 level

\section{** Significant at .001 level}

It is noted that the association of all the items with the dimension to which they belong was higher than 0.30 , which indicates that all of the items have a good ability to distinguish, and this indicates the construction validity of the scale. 


\section{Third: factor validity}

Factor validity was also verified by applying Factor Analysis procedures using the Principal Components method and deliberate rotation using the Varimax method, it is the most common method for estimating explained variance to ensure the construct validity of the list, and Table (4) shows the results of the factor analysis.

Table 4. The factor analysis results show the Latent roots and the variation before and after the sample's rotation

\begin{tabular}{lllllllll}
\hline $\mathrm{N}$ & \multicolumn{3}{l}{ The scale } & \multicolumn{3}{l}{ The scale before rotation } & \multicolumn{2}{l}{ After rotation } \\
& $\begin{array}{l}\text { Dimension * number } \\
\text { of items }\end{array}$ & $\begin{array}{l}\text { Latent } \\
\text { root }\end{array}$ & $\begin{array}{l}\text { Contrast } \\
\text { Ratio\% }\end{array}$ & $\begin{array}{l}\text { Cumulative } \\
\text { variance }\end{array}$ & $\begin{array}{l}\text { Latent } \\
\text { root }\end{array}$ & $\begin{array}{l}\text { Contrast } \\
\text { Ratio\% }\end{array}$ & $\begin{array}{l}\text { Cumulative } \\
\text { variance }\end{array}$ \\
\hline 1 & Realistic & 18 & 17.095 & 24.775 & 24.775 & 6.953 & 10.077 & 10.077 \\
2 & Mental & 14 & 4.843 & 7.019 & 31.794 & 6.635 & 9.616 & 19.693 \\
3 & Social & 9 & 3.470 & 5.028 & 36.823 & 5.269 & 7.636 & 27.329 \\
4 & Traditional & 9 & 2.976 & 4.313 & 41.136 & 4.925 & 7.138 & 34.468 \\
5 & Adventurous & 9 & 2.509 & 3.636 & 44.772 & 4.722 & 6.843 & 41.311 \\
6 & Artistic & 10 & 2.282 & 3.307 & 48.079 & 4.670 & 6.769 & 48.079
\end{tabular}

* The number of items on each scale

It is clear from the Table and the analysis of the results of the factor analysis that the Holland list items produced six factors, which are the factors that have latent roots more significant than "one," it also appears that the largest factor in which the items are saturated, and the largest factor that contributed to the prediction of the list is the first (realistic) factor. This factor contributed a variation of $10 \%$ of the overall scale after rotating the axes, while these factors combined contributed to the interpretation of $48.079 \%$ of the overall variance, a percentage acceptable for study purposes.

Table 5. Factors extracted after rotation for John Holland's occupational preferences list

\begin{tabular}{cllllllllllllll}
\hline Item N & \multicolumn{2}{l}{ Factors } & \multicolumn{1}{c}{ Item N } & \multicolumn{1}{l}{ Factors } \\
& 1 & 2 & 3 & 4 & 5 & 6 & & 1 & 2 & 3 & 4 & 5 & 6 \\
\hline 1 & .95 & .13 & .202 & .385 & .221 & .127 & 4 & .082 & .372 & .506 & .624 & .078 & .283 \\
7 & .425 & .815 & .143 & .207 & .128 & .330 & 10 & .156 & .272 & .338 & .489 & .165 & .388 \\
16 & .510 & .548 & .102 & .430 & .196 & .392 & 19 & .348 & .340 & .392 & .440 & .200 & .180 \\
21 & .125 & .435 & .287 & .071 & .453 & .327 & 23 & .202 & .726 & .173 & .174 & .146 & .051 \\
30 & .597 & .292 & .537 & .077 & .020 & .247 & 28 & .296 & .032 & .104 & .692 & .012 & .106 \\
38 & .881 & .423 & .158 & .423 & .402 & .183 & 32 & .132 & .481 & .042 & .517 & .100 & .268 \\
42 & .770 & .326 & .368 & .113 & .133 & .041 & 36 & .466 & .176 & .343 & .684 & .114 & .094 \\
48 & .876 & .233 & .159 & .234 & .101 & .013 & 40 & .937 & .138 & .159 & .036 & .078 & .054 \\
57 & .856 & .064 & .120 & .163 & .107 & .032 & 45 & .966 & .096 & .014 & .027 & .112 & .058 \\
61 & .879 & .142 & .066 & .288 & .042 & .065 & 50 & .019 & .055 & .056 & .919 & .236 & .032 \\
2 & .072 & 532 & .011 & .065 & .671 & .195 & 54 & .137 & .021 & .179 & .870 & .063 & .216 \\
8 & .204 & .595 & .025 & .082 & .455 & .191 & 58 & .956 & .057 & .032 & .003 & .001 & .038 \\
17 & .338 & .189 & .002 & .804 & .027 & .055 & 64 & .845 & .003 & .156 & .419 & .321 & .005 \\
26 & .264 & .535 & .339 & .434 & .132 & .461 & 5 & .108 & .293 & .151 & .287 & .597 & .412 \\
34 & .445 & .616 & .561 & .172 & .131 & .167 & 11 & .058 & .019 & .215 & .328 & .723 & .143 \\
39 & .757 & .168 & .122 & .314 & .070 & .044 & 14 & .036 & .216 & .107 & .220 & .617 & .002 \\
43 & .831 & .743 & .131 & .058 & .062 & .056 & 20 & .019 & .368 & .135 & .232 & .656 & .313 \\
52 & .825 & .593 & .036 & .073 & .138 & .117 & 24 & .123 & .360 & .130 & .415 & .471 & .041 \\
62 & .797 & .658 & .422 & .122 & .059 & .095 & 29 & .485 & .058 & .535 & .032 & .555 & .111
\end{tabular}




\begin{tabular}{cccccccccccccc}
3 & .151 & .096 & .754 & .134 & .207 & .139 & 37 & .176 & .037 & .141 & .091 & .721 & .276 \\
9 & .030 & .368 & .714 & .753 & .081 & .068 & 46 & .303 & .081 & .142 & .029 & .830 & .217 \\
13 & .415 & .293 & .484 & .196 & .046 & .377 & 55 & .232 & .024 & -.072 & .142 & .819 & .158 \\
18 & .369 & .152 & .500 & .010 & .094 & .437 & 59 & .071 & .129 & -.063 & .015 & .880 & .093 \\
22 & .631 & .403 & .540 & .166 & .072 & .038 & 65 & .062 & .022 & .042 & .156 & .944 & .057 \\
27 & .664 & .233 & .441 & .010 & .102 & .295 & 6 & .253 & .216 & .113 & .366 & .217 & .570 \\
31 & .468 & .000 & .427 & .291 & 420 & .169 & 12 & .015 & .020 & .234 & .171 & .207 & .512 \\
35 & .165 & .149 & .827 & .130 & .160 & .134 & 15 & .389 & .132 & .049 & .092 & .074 & .615 \\
44 & .827 & .180 & .339 & .074 & .142 & .016 & 25 & .334 & .141 & .392 & .123 & .029 & .416 \\
49 & .868 & .090 & .722 & .206 & .076 & .143 & 33 & .375 & .402 & .213 & .181 & .320 & .212 \\
53 & .820 & .086 & .205 & .019 & .072 & .100 & 41 & .077 & .411 & .132 & .142 & .069 & .796 \\
63 & .841 & .301 & .130 & .255 & .143 & .101 & 47 & .950 & .063 & .023 & .176 & .047 & .950 \\
& & & & & & & 51 & .055 & .020 & .067 & .144 & .173 & .905 \\
& & & & & & & 56 & .014 & .375 & .054 & .034 & .073 & .847 \\
& & & & & & & 60 & .132 & .019 & .045 & .022 & .166 & .933 \\
& & & & & & & 66 & .032 & .042 & .178 & .058 & .053 & .940 \\
\hline
\end{tabular}

It is noted from Table (5) that the distribution of items shown by the factor analysis is close to the original distribution of the scale.

The second question: What are the indications of the developed scale's reliability in revealing the hearing impaired's professional tendencies, expressed through the method of test/retest and internal consistency?

\section{Second: Reliability}

\section{Reliability of internal consistency (Cronbach Alpha):}

To measure the reliability of the list: Internal consistency coefficients were extracted by the Alpha Cronbach equation, all of which were good and suitable for the study. They are as follows: realistic style (.70), mental style (.70), social style (.63), traditional style (.80), the Adventurer style (.65), Artistic Style (.63).

\section{Reliability using the Alpha Cronbach equation:}

Reliability was calculated using the Cronbach equation, and they were all excellent and suitable for study and are as follows: realistic style (.82), mental style (.75), social style (.66), traditional style (.55), pattern The Adventurer (.88), Artistic Style (.77).

\section{Study procedures}

- $\quad$ The study tool was developed using the Holland Professional Measure.

- $\quad$ Official approvals were taken to apply the study tool.

- $\quad$ The scale was applied to a prospective sample to extract the significance of validity and reliability.

- $\quad$ The scale was applied to the final study sample with teachers' assistance with hearing impairment to interpret sign language information.

- $\quad$ Collecting questionnaires and subjecting them to statistical analysis.

\section{Statistical treatment}

The items' correlations with the dimensions to which they belonged were calculated to answer the first question, and the factor analysis was performed.

The Cronbach alpha equation was used to verify the reliability using the internal consistency method to answer the second question.

To answer the third question: arithmetic averages and standard deviations for the study, sample responses were calculated on the scale dimensions.

To answer the fourth question: the T-test for independent samples was used. 


\section{Results}

Results of the third question: What are the professional preferences of students with hearing impairments enrolled in vocational rehabilitation programs and deaf schools on the John V Holland Occupational Preference List?

To answer this question, the mean and standard deviations of the performance of the sample as a whole and the performance of males and females were calculated on the six measures in the list of occupational preferences so that the six measures show the occupational preferences according to the average of each variable. Table (6) shows the mean and standard deviations for students' performance on the existing scales.

Table 6. The mean and standard deviations for students' performance on the list's scales

\begin{tabular}{lllll}
\hline Dimension & Gender & Mean & Standard deviation & N \\
\hline Traditional & The sample as a whole & 19.94 & 3.99 & 118 \\
& Females & 20.22 & 3.84 & 58 \\
& Males & 19.72 & 4.19 & 60 \\
Social & The sample as a whole & 16.91 & 3.56 & 118 \\
& Females & 16.79 & 4.02 & 58 \\
Artistic & Males & 17.02 & 3.09 & 60 \\
& The sample as a whole & 16.43 & 3.46 & 118 \\
& Females & 15.90 & 3.31 & 58 \\
Realistic & Males & 16.95 & 3.54 & 60 \\
& The sample as a whole & 15.73 & 3.01 & 118 \\
& Females & 16.31 & 2.96 & 58 \\
& Males & 15.17 & 2.97 & 60 \\
Adventurous & The sample as a whole & 15.59 & 2.92 & 118 \\
& Females & 15.47 & 2.92 & 58 \\
& Males & 15.70 & 2.94 & 60 \\
& The sample as a whole & 14.05 & 2.55 & 118 \\
& Females & 13.90 & 2.36 & 58 \\
& Males & 14.20 & 2.74 & 60
\end{tabular}

From the Table, it appears that the professional preferences for the sample as a whole were in the order of the six scales from the top to the lowest: traditional, social, artistic, realistic, adventurous, mental (with mean averages of $(19.94,16.91,15.9,15.9,16.93,15.9,16.9,15.9)$.

Whereas, female occupational preferences were from top to bottom: traditional, social, realistic, artistic, enterprising, and mental, where the arithmetic averages reached: $(20.22,16.80,16.31,15.90,15.47,13.90$, respectively).

The occupational preferences for males in order of the six measures from the top to the lowest were: traditional, social, artistic, realistic, enterprising, mental (with arithmetic averages of $(19.72,15.17,15.70$, respectively).

The fourth question is: Are there statistically significant differences at $(=0.05)$ in performance on the scale of occupational tendencies attributable to the gender variable (male, female)? To answer the question, a test was performed for the independent samples, and the results were as in Table No. (7): 
Table 7. Results of (T) test for differences in occupational preferences between males and females

\begin{tabular}{lllllllll}
\hline Dimension & Gender & Mean & Standard deviation & $\mathrm{N}$ & "T” value & Sig & df & Sig \\
\hline Traditional & Females & 20.22 & 3.84 & 58 & $* 2.096$ & .038 & 116 & In favor of females \\
& Males & 19.72 & 4.19 & 60 & & & & \\
Social & Females & 16.79 & 4.02 & 58 & .644 & .521 & 116 & There are no differences \\
& Males & 17.02 & 3.09 & 60 & & & & \\
Artistic & Females & 15.90 & 3.31 & 58 & .339 & .735 & 116 & There are no differences \\
& Males & 16.95 & 3.54 & 60 & & & & \\
Realistic & Females & 16.31 & 2.96 & 58 & .670 & .504 & 114 & There are no differences \\
& Males & 15.17 & 2.97 & 60 & & & & \\
Adventurous & Females & 15.47 & 2.92 & 58 & .435 & .665 & 116 & There are no differences \\
& Males & 15.70 & 2.94 & 60 & & & & \\
Mental & Females & 13.90 & 2.36 & 58 & 1.668 & .098 & 116 & There are no differences \\
& Males & 14.20 & 2.74 & 60 & & & & \\
\hline
\end{tabular}

* There are statistically significant differences at the level of $(\alpha=0.05)$

It is noted through the results that there are no statistically significant differences between males and females in occupational preferences and that the differences between the average scores of males and females are not statistically significant, except in the traditional dimension where the average females (20.22) were higher than the average of the male scores (19.72).

\section{Discussion of the Results}

First: Discussing the results of the first question: What are the implications of the developed scale's validity in revealing the hearing impaired's professional tendencies, expressed in terms of the content validity, factor validity, and construction validity?

As the results indicated the availability of indications of content validity, construct validity, and factor validity, the researcher, interprets this because the scale was developed based on scientific foundations consistent with hearing-impaired people's characteristics. Also, considering the choice of a qualified sign language interpreter, explaining to students some modern concepts for them, which led to obtaining logical values for the scale, some schools and centers have also been visited by the researcher and clarification of some professions' requirements students. The current study results are consistent with Al-Masoudi's study (2007), whose results indicated that the professional tendencies' scale has high validity and reliability. The results of the current study are also consistent with the study of Al-Masoudi and Tannous (2015), which indicated that the scale had high validity and reliability indications, as the current study agreed with the study of Al-Masoudi and Tannous (2015), despite the different characteristics of the sample. Still, the scale enjoyed the significance of validity and reliability.

Second: Discussing the results of the second question: What are the indications of the reliability of the developed scale in revealing the professional tendencies of hearing-impaired people, expressed in a test/retest and internal consistency?

As the results indicated that the scale has a high degree of reliability, the researcher explains this result to the researcher's commitment to scientific procedures in scientific research and clarification of the items related to the scale by a qualified sign language interpreter. Consideration has also been given to creating the appropriate environmental conditions to apply the scale to the exploratory sample, as this result is consistent with the Sverko \& Toni study (2006) in which the study tool showed high reliability on all menu patterns, and also consistent with the study of Al-Shahri (2010), which reached acceptable psychometric properties of the study tool.

Third: Discussion of the third question's results: What are the professional preferences of students with hearing-impaired enrolled in vocational rehabilitation programs and deaf schools on the list of occupational preferences of John Holland?

The results of the study showed that the professional preferences for the sample as a whole were in the order of the six measures from the top to the lowest: traditional, social, artistic, realistic, adventurous, and mental; as a result, showed that the traditional pattern is the highest in the professional preferences for the hearing-impairment, while the mental pattern is the lowest in the professional preferences, the researcher 
believes that this is logical that is compatible with the characteristics of people with hearing disability, as this character (traditional) is distinguished by a high ability to exercise self-control and a keen interest in regulations and avoid activities that require high social skills, working in the traditional occupational environment requires systematic data development and accuracy in performance and following instructions such as accounting, business, and banking professions. People with hearing impairment lack language, which is a prerequisite for communication in the professional environment. Therefore, the hearing impaired's orientation was towards the traditional style, whereas the artistic style was at the lowest level in the professional preferences of the hearing-impaired. This result is logical as feelings and sensations characterize the artistic style, avoiding situations that require organizational skills, physical strength, high verbal skills, and a low capacity for self-control. Work in the technical environment requires the use of creative skills that depend on sense, feelings, and imagination; For self-expression, including literary and musical works, this is not compatible with the characteristics of the hearing impaired, as this pattern requires language ability and ability to communicate, as this result indicates that the current scale is proportional to the characteristics of the hearing impaired. This finding is consistent with Walter and Bochner (2005), which concluded that there are no scales appropriate for the characteristics of the hearing impaired; the result of the study differed with the study of Abdul Hamid study (2003), which indicated that there are differences between students in different disciplines in occupational preference, where the results were in favor of scientific on the mental pattern and in favor of literary specialization in the social style and in favor of industrial specialization in the realistic style and in favor of commercial specialization in the adventurer pattern. The researcher considers the difference of the results to be logical due to the difference in the sample characteristics, as the hearing impaired differs from the ordinary individuals, and therefore this difference affects the course of professional tendencies.

Fourth: Discussing the results of the fourth question: Are there statistically significant differences at $(\alpha=0.05)$ in performance on the scale of professional tendencies attributable to the gender variable (male, female)?

The results showed that there are no statistically significant differences between males and females in occupational preferences and that the differences between the average grades of males and females are not statistically significant, as the occupational preferences for females were from top to lowest as follows: Traditional, social, realistic, artistic, adventurous, mental. The occupational preferences for males in order of the six scales from the top to the lowest were: traditional, social, artistic, realistic, enterprising, mental, where the occupational preferences of the traditional pattern are the highest by males and females while the mental pattern is the lowest in the professional preferences where the presence of the disability and the characteristics of the hearing disability are characteristics that apply to males and females such as lack of language and communication and emotional expression affected the professional tendencies of people with hearing disabilities other than males or females, as the male and female professional preferences for patterns that do not require social contact with others, this result is consistent with the study of Ohashi, 2009, which indicated that there are no statistically significant differences attributable to the gender variable in the professional preferences of Japanese students in American schools, which may be the cause Agreeing with the different characteristics of the sample in the presence of a variety of career options that are not limited to males, but can be practiced by females.

\section{Recommendations}

\subsection{Educational Recommendations}

- The necessity of providing deaf schools with the necessary standards to detect the professional tendencies of deaf people.

- Providing training courses for deaf teachers to reveal professional tendencies.

- Providing deaf students with a scientific subject related to the available professions and each profession's requirements.

- Intensifying field visits for deaf students to learn about different work environments such as factories, libraries, etc.

- Work on adapting and adjusting some professions to suit the deaf.

- Providing workers in different professions with free sign language courses facilitates the integration of deaf people in the professional community. 


\subsection{Research Recommendations}

- Work to develop and build standards related to the professional dispositions of the deaf.

- $\quad$ Standardize foreign standards for assessing the professional tendencies of deaf people.

- Study of other variables such as the educational qualification of parents, the geographical environment, and its effect on the professional tendencies of the deaf.

- Examine the differences in occupational tendencies between the disability categories.

- Study the needs of the deaf in the work environment.

\section{References}

Abdul Hamid, I. (2003). Professional interests, a comparative study by specialization, academic achievement, and parenting education for a sample of female students. Journal of Social Affairs, (79), 110-146.

Abdul Qadir, I. (2003). The standards for the hearing-impaired professional qualification, the extent of their application in governmental vocational rehabilitation and employment centers for persons with disabilities in Jordan, and the obstacles to their application (Unpublished Ph. D. dissertation). Amman Arab University, Amman, Jordan.

Al-Ali, S. (2010). The Jordanian image's effectiveness from the adaptive behavior assessment system to reveal the deficiencies in the adaptive behavior skills of individuals with different disabilities (unpublished doctoral thesis). University of Jordan - Amman, Jordan.

Al-Khatib, J. (2002). Introduction to hearing disability. Oman: Dar Al Fikr for publication and distribution.

Al-Masoudi, H., \& Tannous, A. (2015). Codifying the list of occupational preferences of John Holland for the Jordanian environment. Journal of Studies, Educational Sciences, 42(1), 85-107. https://doi.org/10.12816/0017338

Al-Masoudi, H. (2007). Psychometric characteristics of the self-directed test of professional tendencies in the Saudi environment (unpublished master thesis). University of Mu'tah, Jordan.

Al-Rusan, F. (2018). Measurement and Diagnostic Methods in Special Education. Amman: Dar Al-Fikr for Publishing and Distribution.

Al-Sartawi, A., Al-Qaryouti, I., \& Abu Hilal, M. (1996). Rehabilitation and employment services in the Emirates and Jordan. Contemporary education, 13(42).

Al-Shahri, A. (2010). The psychometric characteristics of the Saudi environment's VIP career preferences list (unpublished Master's thesis). Mu'tah University, Karak, Jordan.

Al-Zare', N. (2006). Rehabilitation of people with special needs. Amman: Dar Al-Fikr.

Alzumt, Y. (2005). Vocational Rehabilitation for the Disabled. 2nd edition, Amman: Dar Al-Fikr.

Bochner, Joseph H., \& Walter, Gerard. (2005). Evaluating Deaf Students' Readiness to Meet the English Language and Literacy Demands of Postsecondary Educational Programs. Journal of Deaf Studies and Deaf Education, 10(3), 232-243. https://doi.org/10.1093/deafed/eni025

Baranauskiene, I., Radzeviciene, L., Valaikiene, A., \& Kossewska, J. (2012). The holistic approach to the vocational counseling of students with special education needs. Social welfare interdisciplinary approach, 2(1), 109-122.

Cook, E. (2013). The Gendered Context of Life: Implication for Women's and Men's Career-Life Plans. The career Development Quartly, (41), 227-237. https://doi.org/10.1002/j.2161-0045.1993.tb00373.x

Dababneh, W. (2006). Evaluation of Vocational Rehabilitation Services for the Hearing Impaired in Jordan (Unpublished Master Thesis). Amman Arab University for Graduate Studies, Amman, Jordan.

Gilbrige, \& Stensrud. (2012). People with Disability in Workplace in Randle parker and Jeanne Boland Patterson (Eds.), Rehabilitation Counseling: Basics \& beyond. Austin: pro-ed Publisher.

Hein, S., Lusting, D., \& Uruk, A. (2005). Consumers Recommendation To Improve Satisfaction With Rehabilitation Services. Rehabilitation Counseling Bulletin, 49(1), 29-30. https://doi.org/10.1177/00343552050490010401 
Hirsch, A., \& Lage, P. (2014). Hollands Secondary Constructs of Vocational Interests and Career Choice Readiness of Secondary Student. Journal of Individuals Differences, 28(4), 205-218. https://doi.org/10.1027/1614-0001.28.4.205

Homa, L. (2004). The Impact of Vocational Evaluation on Outcomes in the of Vocational Rehabilition Services program (Unpublished Doctoral Dissertation). Ilion's Institute of Technology, Chicago, USA.

Jarwan, F., Amayreh, G., Al-Hiyari, H., Al Khomrah, Q., Meqdad, S., Alywat, S., \& Al-Tabbal, S. (2013). Students with special needs. Amman: Dar Al-Fikr.

Kavin, D., \& Kurz, K. (2008). The Career Experiences of Deaf Supervisors in Education and Social service Professions: choices, Mobility, and Networking A Quality Study. Jabara Rochester, 42(1), 24-47.

Langman, C. (2012). Introduction to Vocational Rehabilitation: Policies, Practices, and Skills. London: Routledge. https://doi.org/10.4324/9780203804421

Moores, D. (2008). Educating the Deaf: Psychology, Principles, and Practices. Boston: Houghton Mifflin Company.

Mursi, S. (1983). Psychological counseling and educational and vocational guidance. Cairo: Al-Khanji Library.

Ohashi, T. (2009). The Effect of Holland RIASEC Intrest on Vocational identity Development of Japanese High School Students (Unpublished PH. D. Dissertation). The College of Education, Ohio University, USA.

Rihani, S. (2010). Guidance for people with special needs and their families. Amman: Dar Al Fikr.

Spokane, A. R., \& Cruza-Guet, M. C. (2005). Holland's theory of vocational personalities in work environments. In S. D. Brown \& R. T. Lent (Eds.), Career development and counseling: Putting theory and research to work (pp. 24-41). Hoboken, NJ: Wiley.

Sverko. I., \& Babrovic, T. (2009). The Validity of Holland Theory in Croatia. Journal of Career Assessment, 14, 490-507. https://doi.org/10.1177/1069072706288940

Zureikat, I. (2015). Vocational rehabilitation and transportation services for persons with disabilities. Amman: Al Masirah House for Publishing and Distribution.

\section{Copyrights}

Copyright for this article is retained by the author(s), with first publication rights granted to the journal.

This is an open-access article distributed under the terms and conditions of the Creative Commons Attribution license (http://creativecommons.org/licenses/by/4.0/). 